\title{
The Net Benefit to Government of Higher Education: A "Balance Sheet" Approach
}

\author{
David Johnson and Roger Wilkins \\ Melbourne Institute of Applied Economic and Social Research \\ The University of Melbourne
}

Melbourne Institute Working Paper No. 5/02

ISSN 1328-4991

ISBN 0734015291

May 2002

Melbourne Institute of Applied Economic and Social Research The University of Melbourne

Victoria 3010 Australia

Telephone (03) 83443701

Fax (03) 83445630

Email melb-inst@unimelb.edu.au

WWW Address http://www.melbourneinstitute.com 


\begin{abstract}
This paper attempts to establish the fiscal position of the Commonwealth government with respect to higher education in Australia by comparing the cost and revenue streams associated with university education. Costs primarily comprise the government outlays that are used to finance teaching in universities. Less obviously, revenue primarily derives from the productivity-enhancing effects of higher education, which act to increase earnings and hence increase the taxation revenue obtained from university graduates. The effects of higher education on the government budget are examined adopting two alternative perspectives. The first, which we term the "current net benefit" approach, examines contemporaneous cost and revenue flows by comparing higher education expenditure in each year with the additional tax revenue accruing to the government in that year from all university graduates. The second approach, which we call the "cohort net benefit" approach, involves comparison of the costs of a specific student cohort with the anticipated additional tax receipts from that cohort in the future. Our analysis suggests that, under plausible assumptions, the current net benefit to the government of higher education is in excess of $\$ 9$ billion per year, while the expected rate of return on the cohort of students entering higher education in 1999 is $10.9 \%$ per year.
\end{abstract}




\section{Introduction}

An important policy decision for government concerns the extent to which public resources are allocated to higher education. Although a number of factors will affect this decision, key among them is the desire to maximise the return to society from investment in higher education. ${ }^{1}$ Returns to higher education derive from several sources, perhaps the most important of which is the increased productivity (and hence earnings) of the higher education recipients. These returns accrue primarily to the student, and as such, students may derive considerable private benefits from government spending on higher education. However, additional benefits to society as a whole may also derive from the student's higher education, for example because it leads to increased taxation revenue, reduced welfare dependence and a lower propensity to commit crime. Associated with private and societal benefits are calculations of private and societal rates of return. While, from an efficiency perspective, the government is properly guided by the societal return in determining the level of support, the government is also concerned about the effect of policy on the government budget at both the current point in time and into the future. In this paper we focus on the effect of government higher education spending on its own "balance sheet".

The framework adopted considers, from a government perspective, the revenue and cost streams in each year that are associated with university education. ${ }^{2}$ Costs are primarily determined by each year's funding decisions, while revenue depends on the taxation derived from the higher earnings of graduates and on the repayments of HECS debts. ${ }^{3}$ However, while current year costs relate to the current cohort of students, current year revenue is related to past enrolments and the earnings of past graduates. As a corollary, the revenue benefits of current funding arrangements are not derived in the funding year (for the most part), but will be distributed over future years. This suggests two approaches. In the first, which we term the "current net benefit" approach, current costs are compared to current returns, where the returns are related to degrees earned in the past. In the second approach, which we term the "cohort net benefit" approach, the net contribution of a specific student cohort is considered.

\footnotetext{
${ }^{1}$ Equity considerations also play a particularly important role in determining higher education funding policy.

${ }^{2}$ An accountant would most likely disagree with our characterisation of a comparison of cost and revenue flows as a "balance sheet" approach, but we believe the term conveys well the basic idea behind the study.

${ }^{3}$ Throughout this paper the focus is on federal government expenditure on higher education. As such, state government financial contributions to higher education, which are relatively small, are ignored.
} 
Borland et al (2000) present a balance sheet to show the current net fiscal benefit to the Commonwealth government associated with all higher education. In the first part of this paper we build on this balance sheet approach by producing separate estimates of the net fiscal benefit to the government associated with each broad field of study. In the second part of the paper, we present the alternative perspective on the fiscal position of the government with respect to each field of study, wherein we estimate the net benefit associated with each discipline area for a specific (recent) cohort of students.

\subsection{Current net benefit}

The current net benefit is evaluated by considering the contemporaneous cost and revenue streams associated with each field of university study. Costs to the government associated with higher education comprise both direct financial support of universities and support of students via Austudy and Youth Allowance payments and via the provision of implicit subsidies on HECS debts by charging lower than market rates of interest. Government revenue consists of the higher taxes paid on consumption and income that derive from the increased earnings facilitated by higher education. Adopting the position that higher education delivers additional taxation revenue allows us to interpret the cost to the government associated with higher education as an investment.

The disaggregation of costs and revenue by discipline area is based on a number of data sets and some fairly strong assumptions that we detail below. Because of the tentative links between the data and the object, and the strength of the assumptions required, the results should be treated with caution.

The basic methodology uses a benefit-cost framework that is depicted by the following equation:

$$
\text { Netbenefit }=\sum_{k=1}^{K} B_{k}-\sum_{l=1}^{L} C_{l}
$$

where $B_{k}$ is a vector of $k$ benefits and $C_{l}$ is a vector of $l$ costs. In this analysis we obtain separate estimates of Netbenefit for each of eight disciplines.

To calculate current net benefit we focus on the benefits and costs in a particular year and how this might change over time. Expenditure undertaken and revenue received by government occurs on a continuous basis and benefits and costs are not attached to particular investments or indeed cohorts of students. The revenue in a particular year reflects the 
outcome of continuing investments made over all past years and these are compared to current expenditure.

Thus, an advantage of this approach is that benefits and costs are contemporaneous and no judgements concerning the time value of money are required. The limitation is that the results cannot be meaningfully attached to a particular cohort or indeed, a particular set of policies (since the results are the outcome of policies over very many previous years). Nevertheless, the outcomes can be interpreted with respect to the current budget situation and that is the motivation for this part of the analysis.

Using this cost-benefit framework, costs are assumed to comprise the current-year expenditure on universities (both capital and current accounts) and total HECS debts acquired by students in the current year. Benefits are assumed to comprise the increased taxes on increased earnings as well as repayments of HECS debts. Increased tax revenue is calculated from marginal tax rates and estimates of increased earnings. Estimates of increased earnings are derived from a comparison of actual earnings of graduates and non-graduates by discipline, an assessment of the value of the difference in ability between the graduates and non-graduates and estimates of graduate employment levels in each year.

It is important to emphasise that the above costs and benefits do not constitute all costs and benefits to the government that are associated with higher education. In particular, for none of the analysis (including cohort net benefit calculations) do we consider potential external benefits of higher education (for example, a lower crime rate), potential indirect costs and benefits of higher education (for example, lower per capita health care costs to the government), nor the potential implications of higher education attainment levels for the welfare system (which may be substantial). For this reason, we suspect our estimates may understate the true net benefit to the government of higher education.

\subsection{Cohort net benefit}

Measurement of the cohort net revenue benefit involves consideration of the costs and revenues attached to a particular generation, or cohort, of students. As with the estimation of the current net benefit, the costs of government investment in the education of the cohort are compared to the revenue stream remitted to government in tax payments and HECS repayments. However, revenue and cost calculations relate to the entire "life" of a particular cohort, as opposed to all revenue and costs associated with higher education in a specific year (which implicitly compares the costs of all students in the current year with the revenue in the 
current year deriving from all previous students). The comparison of the costs and benefits may be undertaken in one of two main ways: either the rate of interest is determined that equates the benefits and costs (usually called the internal rate of return) so that Netbenefit in the equation above is zero, or a discount rate is assumed and applied to each of the streams and Netbenefit is calculated. The first method requires the researcher to interpret the calculated rate of interest. Often this will be done relative to, say, long-term bond rates. In the second method the researcher must choose an appropriate discount rate to render the calculation meaningful. In either circumstance the researcher's value judgement is critical in determining or interpreting the result. In this paper we calculate an internal rate of return.

\subsection{Plan of the paper}

In the next section we outline the method for obtaining estimates of government costs and benefits. The third section describes the data we have at our disposal and some of the simplifying assumptions, primarily to do with the matching of data from various sources. The results of calculations of the current net benefit are presented in Section 4. Section 5 is concerned with the calculation and presentation of results using the cohort net benefit method. In the first part of the section we outline some additional methodology and in the second part we present the results. The final section of the paper discusses the results and concludes.

\section{Methodology}

The following provides the conceptual framework for the determination of costs to the government of each field of higher education study, and the revenue derived by the government as a result of the education in each field. The framework adopted is to a significant extent dictated by the data available, and so is discussed with reference to the data to be used (although detailed discussion of the data itself is deferred until Section 3 and Appendix 2). Details of the specific formulae employed to estimate costs and revenue are provided in Appendix 1.

\subsection{Costs}

The total cost to the government in each field in each year is equal to the sum of the costs of each field across all universities. Given the absence of direct information on the cost to the government in each year of each field at each university, estimates are derived using information on government funding of each university, the share of university funds allocated to research (versus teaching), and enrolments and student-staff ratios by field of study for 
each university. The assumption employed in order to identify the cost of each field at each university from this information is that costs are directly proportional to the number of teaching staff in the field at the university. Details of the data and the methodology used to identify field costs in each year are as follows.

The total teaching cost to the government of a university in a particular year is calculated as being equal to the total government funding of the university in that year less funding used for research purposes. Total government funding of each university is calculated using information about total direct Commonwealth government grants to the universities in each year and the value of university receipts from the Higher Education Contribution Scheme trust fund in the corresponding year, while funding for research purposes is estimated based on total funding of the university, and the research share of expenditure for the university in 1998, the research share for all universities in 1998, and the research share for all universities in all other years. The research percentage for a particular university may change over time but the research intensity of a university with respect to another remains constant over the period of the analysis. This information is reported in DETYA (1998), DETYA (1989-1993) and DETYA (1994-2000a). ${ }^{4}$

Payments from the HECS trust fund represent the deferred HECS payments of students, which the government pays to universities on behalf of students (with students then acquiring a debt to the government which in total is equal to the total payments from the trust fund). While this is not strictly speaking an expense for the government, since these payments are to be repaid by students (although at a subsidised rate of interest, and only if the student earns a sufficient amount while resident in Australia), a more accurate picture of the fiscal position of the government with respect to higher education is obtained by treating payments from the trust fund as a cost, and treating later repayments as revenue.

Given the teaching cost to the government in each year at each university, we calculate the cost by field using the number of students enrolled in each field and the associated studentstaff ratio, both of which are available from DETYA (1989-1993) and DETYA (1994-2000b). Essentially, a field's share of the total teaching cost at a particular university and in a

\footnotetext{
${ }^{4}$ The research share of funds aggregated across all universities is available for each year, but only in 1998 is it available disaggregated by university. This approach therefore makes full use of the data available, by allowing the research share to differ between universities in proportion to the differences in 1998, and also allowing it to vary across time according to movements in the aggregate research share of funding. Only to the extent that movements over time in the research share differ between universities will inaccuracies arise.
} 
particular year is equal to that field's share of total teaching staff at that university in that year.

This approach permits variation in costs by field to arise because of both differences in costs across institutions and also differences in costs across fields within institutions. The important assumption which enables estimation of the cost of each field is the assumption with respect to the relative costs of the fields within an institution - specifically, that per student costs are directly (inversely) proportional to the student-staff ratio. ${ }^{5}$ Alternative assumptions could be made by altering the functional form of the relation between student-staff ratios and relative cost, for example by assuming a component of university costs that is evenly distributed across all students at the university. Our method could also be modified to include other factors, such as whether study for a field involves laboratory work. However, in the absence of additional information on which to base such augmentations, the simple approach is used.

\subsection{Revenue}

Additional revenue, flowing to the federal government as a result of tertiary education, is calculated for each field of qualification. The intuition for the approach is that tertiary education increases the productivity and hence earnings of individuals, leading to higher taxation revenue for the government. HECS repayments also need to be included in calculations of government revenue from tertiary education.

The average graduate wage in each year is not observed in the available data, but is derived based on knowledge of the average wage over both graduates and non-graduate wages and the proportion of employees who are graduates, and an assumption regarding the (time invariant) "mark-up" of the mean graduate wage over the mean non-graduate wage. In the first instance we adopt a mark-up of sixty percent. ${ }^{6}$

\footnotetext{
5 The precise assumptions regarding the relative costs of the fields within an institution are embodied in Equation (3) in Appendix 1, in which we implicitly assume per student costs are directly (inversely) proportional to the student-staff ratio. Alternative assumptions could be made by altering the functional form of this equation, or including other variables in the equation to capture the effects of other factors.

${ }^{6}$ The estimate of a mark-up of 60 percent is derived from consideration of two surveys. In the 1993 Survey of Training and Education (hereafter STE93), the average income of graduates was $\$ 815$ compared to $\$ 512$ for non-graduates, implying a premium of approximately 60 percent. Graduate respondents to the 1997-8 Income Distribution Survey (hereafter IDS97) earned an average of $\$ 882$ compared to $\$ 496$ for non-graduates, a somewhat larger mark-up of approximately 78 percent. We use the more conservative figure.
} 


\section{Average graduate wages in each year by field of qualification}

The mean graduate wage in a given year can be expressed as a weighted average of the mean graduate wages by field. In the absence of data for each year on graduate wages and employment shares by field, the mean graduate wage and employment share are identified for each field using data from the 1993 ABS Survey of Training and Education (STE93), which gathered information about graduate and non-graduate wages and field of study. In particular, it is assumed that both relative wages across fields, and the proportion of graduates with qualifications in each field, are not time varying and are given by their values in STE93. Thus, the mean graduate wage for a field in a particular year is equal to a multiple of the aggregate mean graduate wage in that year, with that multiple the same as occurs for that field in the STE93. Likewise, the proportion of graduate workers attributed to each field in each year is equal to a fraction of the number of graduates employed in that year, with that fraction the same as occurs for that field in the STE93. ${ }^{7}$

\section{Increase in average earnings}

The increase in the mean wage of graduates over non-graduates by field in each year is calculated using the aggregate mean wage, the "mark-up" and the relative mean wage of each field.

Calculation of the increase in average earnings which derives from higher education requires estimation of the wage graduates would on average earn if they did not undertake higher education. Graduates are likely to have greater innate ability and therefore capacity to earn income than the workforce in general, which implies average wages in the absence of higher education would be higher than the actual average for non-graduates. We therefore allow for greater innate ability of graduates compared with non-graduates, defining it by a proportion of the non-graduate wage. Specifically, the wage of a graduate in the absence of a degree (the "counterfactual" wage) is assumed equal to the mean wage of non-graduates multiplied by one plus this proportion (the "ability mark-up"). Thus, graduates are assumed to on average earn more than non-graduates even if they do not undertake higher education. The ability

\footnotetext{
${ }^{7}$ Earnings are censored above $\$ 1160$ per week in the STE93. Censored observations have been assigned earnings equal to a multiple of $\$ 1160$, with a different multiple for each of 7 education groups. The multiple is based on estimates of the appropriate multiple from the 1994 Income and Housing Costs Survey (IDS94). Specifically, for each education group, we find the proportion of observations that are censored in STE93, and then find the wage with the same proportion of observations above it in the IDS94. We then compute the multiple as the ratio of the mean earnings of these observations to the lower bound wage. Details are available from the authors on request.)
} 
mark-up is a characteristic of graduates, and not of their field of study, so it applies to all fields, and it is assumed time-invariant. Using this information, we can deduce the earnings increase due to the productivity effects of education for each field of study.

The assumption on the ability mark-up is critical to the estimated effect of a degree on earnings, since it determines "counterfactual" earnings: what the graduate would have earned in the absence of the degree. By definition, this counterfactual is not known, but previous research suggests that approximately 80 percent of the earnings advantage of graduates over non-graduates derives from the effects of the higher education, implying an ability mark-up of 0.12 (i.e. $20 \%$ of the 0.6 graduate wage mark-up). ${ }^{8}$ This is therefore the assumed value of the ability mark-up in this study, although sensitivity tests conducted for alternative assumptions are presented in Section 6. Also implicit is the assumption of no systematic differences in innate ability, and hence counterfactual earnings, across fields. This may not be the case. One possible variation, which permits innate ability to differ across fields, is to have the wage for graduates in the absence of a degree vary by field in the same manner as actual graduate wages. This approach takes the view that innate ability differs between the fields in the same proportions as the effects of education on earnings differ by field.

\section{Revenue to the Government}

The additional revenue to the federal government associated with higher education in each field is equal to the taxes on the increased income resulting from the productivity enhancements associated with the degree. The revenue is calculated from the number of fulltime equivalent employees with a degree in each field and year, the difference between the (direct and indirect) tax payments associated with actual and "counterfactual" graduate mean weekly wage levels (assuming weekly wages are sustained over the full year), and the estimated HECS repayments by graduates with qualifications in each field and year.

The number of full-time equivalent employees in a field is the product of the proportion of the population with a bachelor's degree or higher in each year (obtained from ABS (2001a)), the proportion of degree-holders with a degree in each field in the STE93 and the number of fulltime equivalent employees in Australia, obtained from ABS (2001b). It is assumed that two

\footnotetext{
${ }^{8}$ Our estimate of the return to education net of the effects of innate ability derive from two sources cited in Borland et al (2000). Karmel (1995), using data from the Youth in Transition Survey, found about one third of the apparent increased return to higher education for both males and females was due to higher innate ability. Miller and Mulvey (1997), using the STE93, found that fifteen percent of the higher return of graduates was due to higher innate ability, based on the assumption that innate ability is measured by computer skill.
} 
part-time jobs equal one full-time job. Tax payments are based on published income tax rates for each year and an assumption that expenditure taxes account for $10 \%$ of income net of income tax and HECS repayments.

For the purposes of estimating the current net benefit, HECS repayments are approximated by assuming $15 \%$ of the estimated debt acquired in a given year is paid upfront, and $70 \%$ is repaid over the following 10 years (with $10 \%$ of this repaid each year). The remaining debt ( $15 \%$ of the total) is assumed to be never repaid, for reasons such as non-participation in the labour force, emigration and death. Repayments by field are assumed proportionate to the share of degree-holders in each field in the STE93. ${ }^{9}$

It is important to note that the use of mean wages as the basis for the calculation of the taxation revenue received by the government will tend to understate revenue. This is primarily because of the effects of the interaction between a dispersed earnings distribution and a progressive income taxation system. The intuition can be explained with reference to the following example: Under the pre-GST taxation system, the combined income tax liability of two workers each earning taxable income of $\$ 50,000$ per annum was $\$ 28,204$. If, instead, the first worker earned nothing and the second worker earned \$100,000 (a mean-preserving increase in dispersion), the combined tax liability would have increased to $\$ 37,602$. Thus, the greater is the dispersion of earnings, the greater is the extent to which the income tax revenue deriving from higher education will be understated in this study.

\footnotetext{
${ }^{9}$ The assumptions regarding HECS repayments are intended only to approximate HECS revenue. Clearly, they do not reflect actual patterns: repayments don't start, on average, until some time after the debt is incurred (because, for various reasons, taxable income immediately following acquisition of the debt is on average not sufficient to require repayment), repayment rates are increasing over time (due to increases in graduate earnings (both within and across graduates over time), and also due to the changes to repayment rules which have occurred) and will depend on earnings by field, and it is now the case that debt per student depends upon field of study. Similarly, although the assumption that $15 \%$ of HECS debt is paid upfront is based on recent DETYA (2000) data, the proportion of HECS debt paid upfront is subject to considerable variation over time, depending to a large extent on the discounts on offer for upfront payments, as well as the magnitude of HECS fees. However, many of these factors are offsetting, and our approach is to try to encapsulate the net effect of these factors. In Section 5, where the net benefits from a specific student cohort are estimated, greater effort is made to accurately project HECS repayments. This task is rendered comparatively more straightforward for the cohort analysis by the greater certainty about the actual acquired debt and repayment rules that apply to that cohort, and is warranted by the greater sensitivity of estimated net benefits to assumptions on repayments. That is, because future costs and benefits are discounted, and HECS repayments occur relatively early on (and are therefore not as heavily discounted as later costs and benefits), projections of HECS repayments are particularly important for the cohort analysis.
} 


\section{Data}

As discussed in Section 2, direct information on costs and revenue to the federal government in each year disaggregated by discipline/field of study is not available, necessitating indirect inferences based on the available data. An indication of the information available was provided in Section 2, motivating the particular methodology employed to identify the net revenue to the government from each field. We now present more detail on the data available in this section and in Appendix 2.

\subsection{Data sources}

Most information comes from the Australian Bureau of Statistics (ABS) and from the Department of Education, Training and Youth Affairs (DETYA).

Costs are based on Commonwealth grants to each university, the Higher Education Contribution Scheme (HECS) income of each university, student enrolment numbers by university and field of study, student-staff ratios by university and field, and information on the share of university expenditure allocated to teaching versus research (either in aggregate or by university). This information is taken from DETYA higher education publications concerned with financing, students and staffing. Note that all DETYA data is for the calendar year, whereas results are presented for the financial year. This mismatch is resolved by taking the mean of the two calendar years containing the relevant financial year. Data on enrolments and student-staff ratios disaggregated by field are difficult to obtain prior to 1989 . Consequently, the focus is on the period $1989-90$ to $2000-01$.

The data used for revenue calculations consist of (sources are shown in parentheses):

- Average weekly ordinary time earnings of full-time employees, each year (ABS, 2001c).

- Number of full-time equivalent employees in each year (ABS, 2001b)

- Proportion of persons with bachelor degrees or higher in each year (ABS, 2001a).

- Average weekly ordinary time earnings of full-time employee graduates by field of qualification, in 1993 only (STE93).

- Number of degree-holders employed by field of qualification, in 1993 only (STE93).

- Tax rates in each year (ATO, 2001)

- HECS repayment rates in each year (DETYA 2000) 


\subsection{Fields of study}

There are two classifications by which enrolments (equivalent full-time student units or EFTSU) are reported in the DETYA publications (DETYA, 1989-1993 and DETYA, 19942000b) over the period 1989 to 1996 that are relevant: "broad field of study" and "academic organisational unit”. EFTSU by broad field of study are what we are interested in, but the categories do not match up exactly with those by which student-staff ratios reported (which are classified by academic organisational unit). From 1997 to 2000, information is produced on enrolments for both "discipline group" and "academic organisational unit", but the categories reported are the same, and these are also the same as for academic organisational unit in 1989 to 1996. The STE93 records the main field of study for highest educational qualification for two different classifications of fields.

The task therefore is to first match the DETYA fields of study categories for 1989 to 1996 with the DETYA discipline group categories for 1997 to 2001 (which simultaneously creates a time-consistent series and a match between categories for enrolments and student-staff ratios in 1989-1996), and then match these categories with those of the STE93 for one of the classifications of fields available in the STE93.

The process of matching fields across data sources (details of which are provided in Appendix 2) yielded the following set of fields, which are used in all of the analysis:

- Administration, business, law

- Education

- Health

- Science

- Agriculture \& related fields

- Engineering

- Architecture \& related fields

- Social sciences, arts, humanities

There are several problems associated with the use of these eight fields, which essentially derive from the aggregated nature of the data available. First, combining all courses into just eight fields is likely to produce some undesirable aggregates. The fields are very broad and include disciplines that may be quite disparate or reflect vastly different earnings capacity 
(e.g. law is with business administration, nursing with medicine). This level of aggregation suggests that great care must be taken interpreting the results, particularly for individual fields.

Second, the data available also include a proportion of enrolments in non-degree courses. Information on enrolments at each institution by course type exists, but is not disaggregated by field of study. Implicitly we make the assumption that, within each institution, the proportion enrolled in degree courses is the same across fields.

A third issue arises from the recent growth in combined and double degrees and changes in the subject content of degrees. While the enrolment data reflect the equivalent full-time resources devoted by each discipline, in reporting the main field of study in the STE93 individuals would not indicate the extent to which a particular degree drew on other disciplines. For instance, economics subjects are widely taken by students in other degrees. The enrolment data will appropriately reflect this, but the STE93 data will not. In the event that the proportion of subjects from other fields remains constant over time, there is no problem. However, if this is not the case, the comparison of income and net benefit by field over time will be compromised. For instance an arts student reporting earnings in 2000 may have a greater component of economics embedded in his degree and therefore in the human capital which dictates his earnings, than a person who graduated in 1990.

\section{Results of current net benefit calculations}

\subsection{Graduate returns}

Table 1 shows the proportion of graduates, the mean weekly wage and the relative wage in each of the eight fields in the STE93.

Table 1 shows the proportion of graduates, the mean weekly wage and the relative wage in each of the eight fields in the STE93. The proportions are used, in conjunction with annual information on employment levels of graduates, to determine employment numbers for graduates in each field. The relative wages form the basis for differences across fields in the increase in earnings deriving from higher education. However, for particular fields, much of the increased earnings will not be in the form of wages and salaries but rather in the form of increased returns from business or self-employment. In professions such as medicine, law and accounting, the graduates earning the highest returns are likely to be self-employed or to own 
businesses. Among these professions, the values recorded below are likely to represent the lower bound of potential earnings.

Another important point to bear in mind when interpreting the table is the degree of aggregation. Thus, while the earnings of those with degrees in health seem moderate they are likely to be dominated by the earnings of relatively lower paid nurses rather than higher paid doctors and surgeons.

The highest earnings are received by those in the business and related field, followed by engineering and architecture and related jobs. The lowest earnings go to those with degrees in the social sciences, arts and humanities.

\begin{tabular}{lccc}
$\begin{array}{l}\text { Table 1: Proportion of graduates in each field of study and mean weekly wages by field of } \\
\text { study, STE93 }\end{array}$ & $\begin{array}{c}\text { Proportion of all } \\
\text { graduates }\end{array}$ & $\begin{array}{c}\text { Mean weekly } \\
\text { wage (\$) }\end{array}$ & $\begin{array}{c}\text { Wage relative to } \\
\text { mean }\end{array}$ \\
\hline Field & & & \\
& 0.214 & 1081.9 & 1.192 \\
Administration, business, law, & 0.224 & 829.0 & 0.914 \\
economics & 0.110 & 846.7 & 0.933 \\
Education & 0.169 & 878.1 & 0.968 \\
Health & 0.019 & 899.1 & 0.991 \\
Science & 0.097 & 1028.3 & 1.133 \\
Agriculture \& related fields & 0.022 & 947.0 & 1.044 \\
Engineering & 0.146 & 791.3 & 0.872 \\
Architecture \& related fields & & 910.9 & \\
Social sciences, arts, humanities & & & \\
All fields & &
\end{tabular}

\subsection{Average costs per student}

Figure 1 shows, for each field, the average annual cost to the government per full-time equivalent student in each of the financial years over the period 1989-90 to 2000-01, expressed in December 2000 prices.

The average costs reflect both the staff-student ratios and the variation in the composition of enrolments by field of study across institutions. For example, fields of study which tend to involve a high level of practical work are likely to have lower student-staff ratios, and courses in fields more likely to be found at small institutions are likely to be more expensive per fulltime student. Agriculture is a field that has both a large practical component and tends to be offered by smaller institutions. It is therefore not surprising that it is one of the most 
expensive fields of study. At the other extreme, business studies and related courses may be presented to large numbers of students per staff member and are offered by large institutions that may achieve economies of scale. The per-student cost of this field was consistently the lowest.

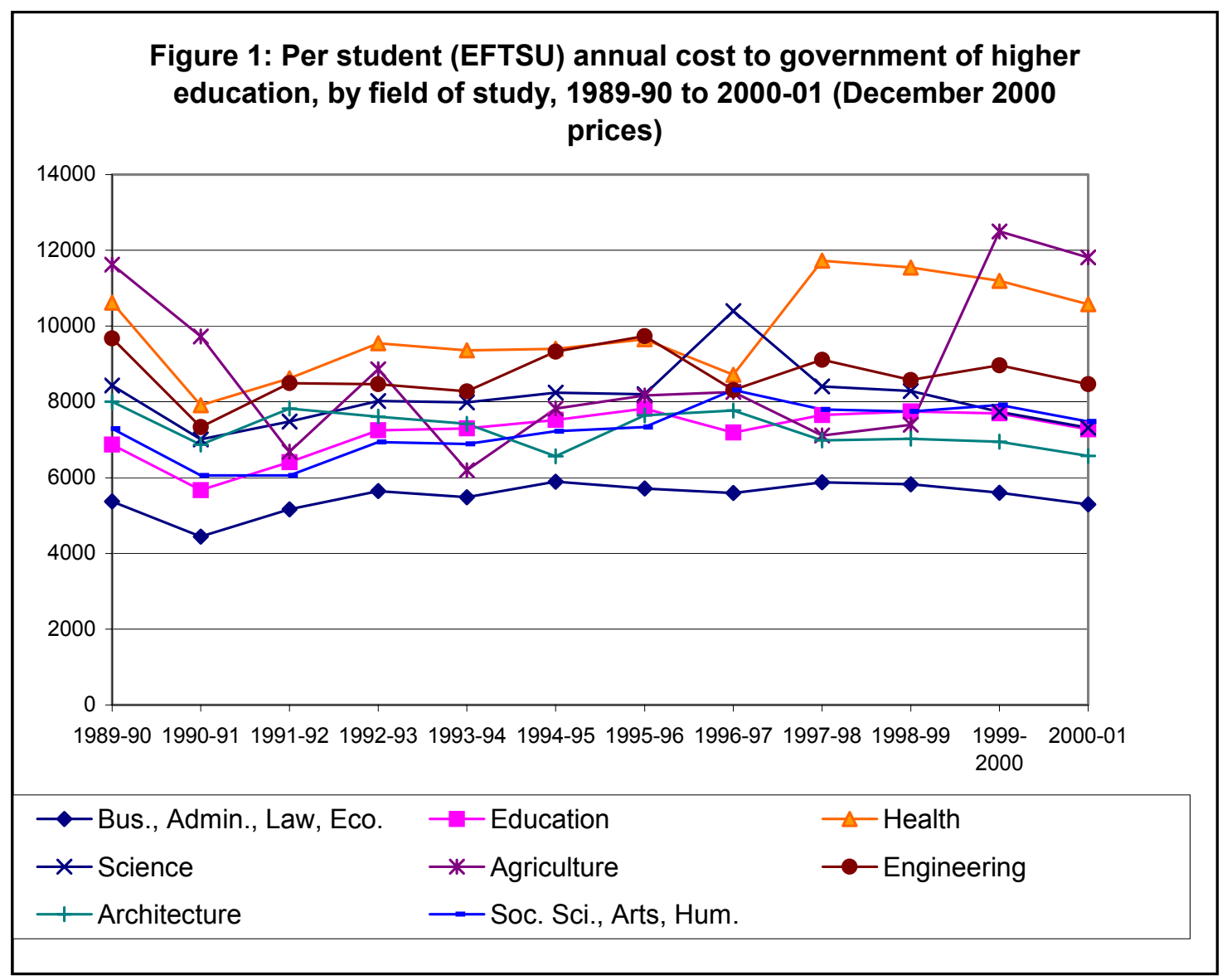

\subsection{Real net benefit to government}

Table 2 shows, at December 2000 prices, the real net benefit to the government by field for the period 1989-90 to 1999-2000, with projections for the following two years and 2010-11. All fields except "social science, arts and the humanities" have a positive net benefit in 19992000. The projections suggest that the net benefit of even this field become positive in the year 2000-01. The real net benefits are highest for the business and related field, reflecting high earnings (see Table 1) and low costs (see Figure 1). 
The table suggests that by 1999-2000 the government balance sheet is improved by over $\$ 8$ billion from the investment in higher education. With unchanged policy, and assuming fixed real per unit costs, the increasing proportions of graduates in the workforce will further add to government balance sheet, so that by 2010 -11 over $\$ 12$ billion will be added each year.

Table 2: Real net benefit per year by field, 1989-90 to 2000-01, \$million (December 2000 prices)

\begin{tabular}{lcccccccccc}
\hline & $\begin{array}{c}\text { Bus., } \\
\text { Admin., }\end{array}$ & \multicolumn{1}{c}{ L } & \multicolumn{3}{c}{ Agriculture } & \multicolumn{3}{c}{ Architecture } & Arts, \\
Year & Law, Eco. & Education & Health & Science & \& related & Engineering & \& related & Hum. & All fields \\
\hline $1989-90$ & 1266 & 370 & -64 & 268 & 11 & 393 & 55 & -224 & 2075 \\
$1990-91$ & 1451 & 514 & 60 & 380 & 23 & 502 & 71 & -116 & 2886 \\
$1991-92$ & 1484 & 544 & 23 & 379 & 50 & 492 & 68 & -113 & 2927 \\
$1992-93$ & 1539 & 573 & -23 & 379 & 35 & 522 & 77 & -182 & 2922 \\
$1993-94$ & 1772 & 672 & 29 & 447 & 66 & 604 & 90 & -157 & 3523 \\
$1994-95$ & 1887 & 761 & 72 & 488 & 58 & 628 & 108 & -176 & 3827 \\
$1995-96$ & 2174 & 904 & 132 & 608 & 72 & 734 & 114 & -142 & 4595 \\
$1996-97$ & 2456 & 1117 & 326 & 390 & 92 & 961 & 128 & -312 & 5158 \\
$1997-98$ & 2773 & 1309 & 354 & 600 & 126 & 1132 & 162 & -251 & 6204 \\
$1998-99$ & 3152 & 1506 & 457 & 784 & 148 & 1306 & 193 & -142 & 7404 \\
$1999-2000$ & 3457 & 1658 & 536 & 952 & 129 & 1412 & 218 & -88 & 8274 \\
$2000-01$ & 3701 & 1786 & 622 & 1099 & 146 & 1508 & 238 & 37 & 9136 \\
$2001-2$ & 3858 & 1868 & 665 & 1173 & 155 & 1572 & 250 & 82 & 9622 \\
$2010-11$ & 4623 & 2311 & 896 & 1560 & 201 & 1886 & 311 & 337 & 12125 \\
\hline
\end{tabular}

The effect on the government balance sheet of returns from all fields is shown in Table 3 . Note that Table 3 is concerned with the contribution of higher education to the federal government balance sheet, whereas some revenue from indirect taxes will have been received by state governments. However, it is still valid to include the effect of these taxes in the balance sheet since increased revenue to state governments may reduce the size of the grants to states by the federal government.

The second and third columns of the table show the government revenue and costs streams with the budget balance (surplus or deficit) in the fourth column. The fifth column shows the net contribution of higher education to the budget position. The last column of the table shows the net contribution of higher education expressed as a percentage of the Commonwealth government revenue. The net contribution of higher education rises from 1.6 percent of 
revenue to 4.7 percent over the period. To an increasing degree, higher education is an important element in achieving budget balance.

Table 3: Contribution of higher education to Commonwealth government balance sheet, \$billion (Dec 2000 prices)

\begin{tabular}{lccccc}
\hline Year & Revenue & Outlays & $\begin{array}{c}\text { Cash } \\
\text { balance }\end{array}$ & $\begin{array}{c}\text { Contribution } \\
\text { of higher } \\
\text { education }\end{array}$ & $\begin{array}{c}\text { Net } \\
\text { contribution as } \\
\text { a proportion of } \\
\text { revenue (\%) }\end{array}$ \\
\hline $1989-90$ & 126.43 & 117.64 & 8.79 & 2.08 & 1.6 \\
$1990-91$ & 121.03 & 120.56 & 0.46 & 2.89 & 2.4 \\
$1991-92$ & 113.45 & 127.58 & -14.14 & 2.93 & 2.6 \\
$1992-93$ & 114.93 & 135.66 & -20.74 & 2.92 & 2.5 \\
$1993-94$ & 119.53 & 139.95 & -20.42 & 3.52 & 2.9 \\
$1994-95$ & 127.71 & 143.06 & -15.34 & 3.83 & 3.0 \\
$1995-96$ & 134.19 & 145.35 & -11.17 & 4.60 & 3.4 \\
$1996-97$ & 141.72 & 147.49 & -5.76 & 5.16 & 3.6 \\
$1997-98$ & 148.57 & 147.29 & 1.28 & 6.20 & 4.2 \\
$1998-99$ & 157.82 & 151.91 & 4.51 & 7.40 & 4.7 \\
$1999-2000$ & 175.45 & 162.05 & 13.41 & 8.27 & 4.7 \\
\hline
\end{tabular}

\subsection{Alternative measures of course costs}

In the analysis undertaken in this paper, field costs have been calculated based on both the funding received in total by each university and the staff-student ratios in each discipline area within each of the universities. A potential alternative method for calculating the course costs is to take advantage of the information contained in the Relative Funding Model (RFM). The RFM provides the basis for government reimbursement of universities based on their student load by discipline. The RFM was derived from sample data gathered in the teaching cost studies in the late 1980s, modified by judgements about the spread of costs.

The unit costs of course delivery for different university undergraduate courses using the RFM are given in Table 4 for 1997. The costs of particular bands relative to the most expensive band are shown in the last column of the table. By comparing this column with the information in Figure 1, it can be seen that there is broad conformity between the methods of estimating costs of fields. For both sources, the courses with significant laboratory components - Agriculture, Medicine, Science and Veterinary Science - are among the most expensive courses, and the cheapest courses are in the social sciences, law and the humanities. 
Unfortunately, the RFM is not likely to provide meaningful results for our analysis for two reasons. First, the classification of disciplines shown in Table 4 cuts across the classification used to estimate government revenue. While it would be possible to formulate an imperfect matching of fields, this would require increased aggregation of fields and would increase the mismatches between the data sources. Second, the RFM provides course costs for all universities. All differences in cost structure between universities are subsumed in Table 2 . Much of the power of the cost calculations in our method derives from using staff-student ratios and total funding at the institutional level, so that differences between universities are preserved.

Table 4: Unit costs of course delivery as per RFM, 1997

\begin{tabular}{lcc}
\hline Band & Teaching unit costs & $\begin{array}{c}\text { Costs as \% of } \\
\text { highest band }\end{array}$ \\
\hline $\begin{array}{l}\text { 1. Accounting, Economics, Law, Other humanities } \\
\begin{array}{l}\text { 2. Behavioural science, Education, Mathematics, Other } \\
\text { social science }\end{array}\end{array}$ & 6250 & 37 \\
$\begin{array}{l}\text { 3. Computing, Nursing, Other built environment, Other } \\
\text { health, Other languages, Visual and performing arts }\end{array}$ & 10000 & 48 \\
$\begin{array}{l}\text { 4. Engineering, Science, Surveying } \\
\text { 5. Agriculture, Dentistry, Medicine, Veterinary Science }\end{array}$ & 13750 & 59 \\
\end{tabular}

\section{Cohort net benefit}

The objective of this section is to forecast, for each major field of study, the net fiscal benefit to the government of investment in higher education for the 1999 entry cohort of students.

The approach is to calculate the internal rate of return (IRR) to the government from investment in higher education based on government expenditure on higher education, HECS revenue and the effects on taxation revenue of higher education study. For each of eight fields of study, the per-student revenue to the federal government net of costs is estimated for each year over the period 1999 to 2045 (the projected date of retirement). The implicit IRR associated with the projected net revenue stream is then calculated for each field such that the net present (discounted) value of the stream is zero. 


\subsection{Method for estimating the projected net revenue ${ }^{10}$}

The analysis is undertaken by examining the fiscal costs and benefits on a per-student basis (at December 2000 prices).

Costs to the government comprise expenditure on higher education and forgone taxation revenue during the period in which the student is engaged in higher education study. Benefits comprise upfront HECS payments, repayments of deferred HECS debts, and additional taxation revenue derived from the higher earnings obtained by the student as a result of the education. As mentioned, the study is of the cohort entering higher education study in 1999, and in particular, the "representative student" is a native-born male commencing a bachelor's degree in 1999 at age 18.

\section{Costs}

Per-student annual expenditure on higher education teaching for each field is based on the total field costs for 1999 (obtained in the earlier analysis of the government balance sheet with respect to each field) and on total enrolments in each field. That is, the per student cost to the government of each year of study for a field is assumed constant over the duration of the course, and equal to the total cost to the government of the field in 1999, divided by the number of (full-time equivalent) enrolments in that field in 1999.

To estimate total course costs per student requires information on course length. In fact, the assumed length of the course is critical not only to estimates of course costs, but also the level and timing of HECS repayments and the net taxation revenue effects of higher education in the early years (calculations for both of which are discussed below). While allowance can be been made for differences in average course length across fields, a difficulty created by the broad nature of the categories is that course lengths vary significantly within each field. For example, the "health sciences" field contains both nursing, a course usually of 3 years duration, and medicine, normally of 6 years duration. Rates of enrolment in combined degrees and postgraduate courses, and failure rates, will also influence costs. Other sources of variation in actual course durations (for example, part-time study) are not so important to cost estimates, since costs are per equivalent full-time student, but they will impact on taxation and HECS revenue streams.

\footnotetext{
${ }^{10}$ Formal description of the methodology is provided in Appendix 1.
} 
For all the analysis, it is assumed that courses in the "health sciences", "agriculture", "engineering" and "architecture" fields are of four years duration, while courses in all other fields are of three and a half years duration. These assumed durations probably understate actual average durations (of full-time equivalent study).

\section{Revenue}

Projections of earnings over the period 1999 to 2045 are used to estimate both the effects on taxation revenue of higher education and also, in conjunction with estimates of accumulated HECS debts, HECS repayments. Projected earnings for an individual commencing higher education in 1999 are based on an earnings equation estimated for native-born male full-time employees aged 15 to 64 using the seven ABS Income Distribution Surveys (IDS) conducted between 1982 and 1997/8. Log weekly wage and salary income (December 2000 prices) is regressed on potential work experience (equal to age minus years of education minus 5) and its square, two dummy variables for highest educational attainment (bachelor's degree or higher, no bachelor's degree), interactions between the education and experience variables, and ten birth cohort dummy variables (before 1930, 1930-34, 1035-39, 1940-44, 1945-49, 1950-54, 1955-59, 1960-64, 1965-69, after 1969), interacted with the education dummies.

The IDS do not contain information on main field of study, ruling out estimation of separate experience-earnings profiles by field of qualification. (The STE93 could have been used, but on its own contains insufficient observations to identify with any degree of precision the effect of experience on earnings for each field.) The birth cohort variables are employed to control for changes to the "quality" composition of degree-holders and other workers over time. For example, it may be that earlier cohorts of degree-holders are of higher average quality than more recent cohorts, leading to upwardly biased estimates of the effect of obtaining a degree at higher levels of experience (which are only composed of workers from early birth cohorts). It is not possible to control for this effect with a single cross-section because of the identification problem created by the equivalence of birth cohort and potential work experience for a given level of education. The use of multiple cross-sections of data obtained at different points in time breaks this one-to-one correspondence and thereby allows separate identification of the effects of birth cohort on earnings.

The restriction to males is motivated by the view that, for females, current earnings profiles are much less likely to be representative of future earnings paths, given the significant 
changes in recent decades in the labour market behaviour of females, something likely to continue.

The coefficient estimates (reported in Appendix 1) are then used to predict the earnings of an individual commencing higher education in 1999 who is assumed to enter full-time employment in 2003 and retire in 2046.

This produces an earnings series for male degree holders in aggregate. Projected earnings are allowed to vary across fields by using the STE93, which has information on main field of study for highest educational qualification. The relative mean wage of each field of study was obtained for full-time employed native-born males aged 15 to 64, and multiplied by the aggregate projected wage at each experience level to produce the projected wages for each field.

The earnings of the individual in the absence of higher education (which we can label as "projected counterfactual earnings") are also predicted, on a similar basis to that employed in the earlier analysis of the contemporaneous net benefit to the government. As per the current net benefit analysis, it is assumed that $80 \%$ of the difference in earnings between degreeholders and others is due to the productivity effect of the degree, with the remaining $20 \%$ the result of differences in innate ability.

In the absence of higher education, potential work experience is assumed to start accumulating in 1999, such that by 2003, when degree-holders (those with 4 year degrees) are assumed to commence employment (with zero years of experience), years of experience equals 4 for the counterfactual earnings stream. That is, the individual is assumed to commence work in 1999 if he does not undertake higher education. It is, however, assumed that individuals who undertake higher education do engage in part-time work while studying, earning $\$ 6000$ per annum, in December 2000 prices, irrespective of field of study. Note that projected earnings make no allowance for productivity growth over time.

\section{Adjustment for unemployment and part-time employment}

Using the pre-GST income tax rates for 1999 and 2000, and the post-GST rates from 2001, the income tax payable in each year for each earnings stream is calculated (i.e. for the projected stream for each field and for the counterfactual projected stream common to all fields). These are then "discounted" by the projected male employment rates by age, which are simply assumed equal to the employment rates by age in IDS97. The "discounting" is implemented by multiplying the tax paid by the full-time equivalent employment rate at the 
relevant age, giving the "employment rate adjusted" tax paid per person. The employment rate is defined as the mean individual employment rate, where non-employment equals an individual employment rate of zero, a part-time job is assumed equal to an individual employment rate of 0.5 and a full-time job corresponds to an individual employment rate of 1 . A problem with this approach is that part-timers will be in lower tax brackets than full-timers, leading to overstatement of tax revenue. That is, the total tax paid by two part-timers, who each earn half as much as one full-timer, will be less than that paid by the full-timer. However, the alternative of discounting earnings (rather than tax paid) by the employment rate would suffer the problem of understating tax revenue, since most of those who do work in a given year will earn more than this discounted earnings measure. A further problem is the likely prospect of tax bracket creep: inflation will reduce the real value of tax bracket thresholds over time. Given uncertainty over future rates of inflation (and indeed income tax rates and thresholds), no attempt is made to address this issue, but it is, nonetheless, acknowledged.

The difference in income tax paid between the projected actual earnings and projected counterfactual earnings in a given year is the per person net income tax revenue benefit of the higher education in that year. Note that this is negative over the period 1999 to 2002, when those undertaking higher education might otherwise be working full-time.

Expenditure tax implications of higher education are calculated based on the assumption that $10 \%$ of the difference in disposable income between projected actual and counterfactual earnings in a given year accrues to the government in the form of additional tax revenue (or is lost when counterfactual earnings exceed actual). Again, this is discounted by the equivalent full-time employment rate.

As in the study of the current net benefit, calculations do not take into account the Medicare levy, and various other surcharges, tax offsets and family allowances, although these are unlikely to have much effect on the overall results.

\section{HECS repayments}

HECS revenue projections for each year require estimates of the total HECS liability incurred and the repayment rates (including the proportion paid upfront). The total HECS liability is based on the assumed course length (discussed above), and current HECS rates. HECS charges currently vary according to course, with one of three "bands" applying to every course. The lowest band applies to arts, social sciences, education and nursing courses, which 
in 2001 incurred HECS charges of $\$ 3521$ per year of full-time study. The highest band in 2001 , for medicine, dentistry and law, was $\$ 5870$ per year. All other courses incur the HECS charges at a rate of $\$ 5015$ per year of full-time study. This classification does not match the fields by which courses are classified in the DETYA and STE data. Here, it is assumed that all courses incur HECS charges of $\$ 5015$ per annum (in December 2000 prices), except courses in the "social sciences, arts, humanities" and "education" fields, which are assumed to incur HECS charges of \$3521 per annum.

Based on DETYA (2000) data, 15\% of HECS debt is assumed paid upfront, reducing HECS debt by $20 \%$ (given the current discount offered by the government for upfront payments). Estimated HECS repayments are based on the projected earnings and the required repayment rates currently in place. As per the income and expenditure tax calculations, repayments are discounted by the equivalent full-time employment rate at each age level by multiplying the repayments in each year by the employment rate.

An issue with the methodology for calculating HECS repayments is that this may not reflect the likely actual average rate of repayment per person. HECS repayment for some individuals will not be completed until a number of years after the year of completion implied by the methodology employed, if at all. The assumption that all debt is on average eventually repaid is also not valid. Some individuals will die, some will emigrate, and some will not earn at a sufficient rate to repay the debt. ${ }^{11}$

\section{Some additional concerns}

There are a number of other assumptions that may influence the estimates:

- The earnings functions are based on past experience and may not represent future earnings streams, for all sorts of (largely unforeseeable) reasons;

- Similarly, the wage relativities by field evident in the STE93 may not hold in the future (for example, they may be changed by supply responses - a possible example of which is the relatively recent surge in enrolments in information technology (computing) courses).

- The average duration of higher education study is higher than is implied by the analysis. To the extent this is because of failures, combined courses ("double degrees"), and

\footnotetext{
${ }^{11}$ The issue of deaths and emigration in fact applies to taxation revenue as well: failure to take these into account leads to overstatement of the net tax revenue benefits, even if we assume the death or emigration would have incurred in the absence of higher education.
} 
postgraduate study, costs for the 1999 entry cohort will be understated. This also affects revenue calculations. The total HECS liability will tend to be understated (thereby understating revenue from repayments), and the estimated year of labour market entry will be earlier than is on average actually the case (thereby overstating net tax revenue benefits in the early years). These are all critical to the results, because they relate to costs and benefits in the early years, which have much more impact on the IRR than those in later years.

- Related to this, results are extremely sensitive to the net revenue outcomes when studying. For example, if we do not consider tax revenue forgone while students are studying, IRR's increase by around a third to a half. Variations to study durations will similarly have large effects.

- Retirement ages are likely to differ between degree-holders and non-degree holders, and to differ by field. This is not allowed for, but is probably not important given the revenue benefits are remote in time from the present, when the costs are incurred.

- Employment rates are assumed the same for individuals regardless of whether higher education is obtained or not. Employment rates are in fact higher for individuals with higher education qualifications than those without. While we might expect the counterfactual employment rate to be higher than the employment rate for those who do not actually obtain higher education, it is unlikely the counterfactual employment rate would be as high as the actual employment rate for degree-holders. This implies understatement of the net tax revenue benefits of higher education. However, one also suspects that the recent expansion in higher education is likely to be associated with a fall in future employment rates by age for degree-holders. It is therefore not clear which employment rates are most appropriate to use. As a sensitivity test, IRR's are also calculated using the employment rates of degree holders as the projected actual employment rates, and those of non-degree holders as the projected counterfactual employment rates. This increases IRR's by between 0.5 and 1.5 percentage points.

- As noted for the current net benefit calculations, the narrow focus on wage and salary income of employees is potentially misleading. Self-employment (and business ownership) is likely to differ between degree-holders and others, and between fields, in both rates of incidence and in earnings. Only under very unlikely special conditions would the results be the same if these groups of workers were taken into account. This would 
perhaps tend to increase the net revenue gain of the government (and hence the IRR), probably most noticeably for architecture, engineering and health (although it may decrease the IRR for other fields like education and social sciences, arts and humanities).

- Also noted in the discussion of the current net benefit calculations, and relevant to cohort net benefit estimates, was that counterfactual earnings are assumed to be the same across fields, which may not be appropriate. For example, it is plausible that counterfactual earnings are correlated with observed earnings.

- The calculations apply only to males. It is arguable that recent trends in female educational attainment patterns and labour force participation suggest some degree of convergence to males over time (such that future projections for females are best approximated using male estimated earnings functions and employment rates), but complete convergence is unlikely.

\subsection{Results}

Table 5 shows the internal rates of return for the eight broad fields of study, based on the methodology described above. Two sets of results are presented. In the column labelled A we show rates of return in which projected actual and counterfactual employment rates are assumed to both be equal to the aggregate 1997 employment rates for males, whereas in column B the projected actual employment rates are assumed to be equal to 1997 employment rates for males with a degree qualification, while projected counterfactual employment rates are assumed equal to 1997 employment rates for males without a degree qualification. The different assumptions about employment rates appear to have little affect on the results and attention is henceforth restricted to the column A results.

The returns are positive for all eight broad fields of study for which it is possible to obtain disaggregated estimates, but vary substantially across the fields. The field "business, administration, economics and law" has the highest estimated internal rate of return, at $18.4 \%$, and "social sciences, arts and humanities" has the lowest, at 3.6\%. These rates of return may be compared with societal discount rates. A common basis of comparison in the current longterm bond rate - that is, the return on government bonds over a reasonably long period (say 10 years). The current long-term bond rate is 5.5 per cent. ${ }^{12}$ Rates of return for all fields of study except "Social sciences, arts and humanities" exceed the long-term bond rate, some by a

\footnotetext{
${ }^{12}$ Australian Financial Review, 30/8/01
} 
considerable margin. The average return over all disciplines of 10.86 percent is nearly double the long-term bond rate. The investment by the government in the current cohort appears to be very profitable.

Table 5: Internal rates of return by main field of study (\%)

(A)

Administration, business, law, economics

Education

Health

Science

Agriculture \& related fields

Engineering

Architecture \& related fields

Social sciences, arts, humanities

All fields
18.42

6.71

8.49

7.95

7.82

10.82

11.32

3.63

10.86
(B)

18.82

7.71

9.16

8.81

8.69

11.46

11.97

5.18

11.54

(A) Projected actual and counterfactual employment rates are assumed to both be equal to the aggregate 1997 employment rates for males.

(B) Projected actual employment rates are assumed equal to 1997 employment rates for males with a degree qualification, while projected counterfactual employment rates are assumed equal to 1997 employment rates for males without a degree qualification.

\section{Concluding comments and further work}

\subsection{Interpretation}

The most challenging aspect of this report is the interpretation of the results. While on the surface it seems that universities provide government with a very large net increase in the budget "bottom line", there are some important limitations of the analysis.

First, the comparison of costs and revenue is not as plain as may seem. For the current net benefit method, the cost (to the government) is based on expenditure on the present cohort of students, whereas the benefits are based on revenue accruing from past cohorts of students. Deriving policy implications is not straightforward, since revenue is largely the outcome of past higher education funding decisions (notwithstanding the potential to alter the structure of the taxation system). A particular risk is that using the current earnings of past student cohorts to infer the likely net benefits from investment in the current student cohort may not be appropriate. For example, the expansion in rates of attainment of higher education in recent decades may be associated with a lower graduate/non-graduate earnings differential in the future. 
There are similar concerns about the rates of return calculated with the cohort net benefit method. Here we are projecting an earnings function from past cohorts on to the current cohort. However, the current cohort of students is a much larger part of the population cohort (all those born at the same time) and it may be that the margin they earn over those not undertaking higher education will be also be affected by the relative size of the student group and will be less.

Second, the omission of self-employed income is important. It will certainly distort the relative returns and costs of fields but may also have an aggregate effect. If self-employed and business income due to education is, on average, greater than that shown by salaries and wages then the returns to individuals and the benefit to government revenue through increased tax revenue will be underestimated. On the other hand, the self-employed may have more opportunity to use various devices to minimise income tax and negate this effect.

Third, the assumption about the earnings graduates would have earned had they not undertaken tertiary education is very strong. The higher this counterfactual wage, the lower will be the increased earnings due to higher education and the lower the increased revenue to government. As a sensitivity check on this assumption, Table 6 reports the aggregate real net benefit in 1999-2000 at four levels of return to innate ability.

Table 6: Sensitivity of aggregate net benefit to assumption about ability mark-up, 1999-2000 (Dec 2000 prices)

\begin{tabular}{lccc}
\hline Ability mark-up $(s)$ & $\begin{array}{c}\text { Revenue to } \\
\text { government, \$million }\end{array}$ & $\begin{array}{c}\text { Cost to government, } \\
\text { \$million }\end{array}$ & $\begin{array}{c}\text { Aggregate net benefit, } \\
\text { \$million }\end{array}$ \\
\hline 0 & 15057 & 4201 & 10857 \\
$12 \%$ & 12476 & 4201 & 8275 \\
$30 \%$ & 8319 & 4201 & 4118 \\
$47 \%$ & 4241 & 4201 & 40 \\
\hline
\end{tabular}

In the first row we show the real net benefit to government, if potential graduates had no innately greater capability than non-graduates and all of the sixty percent mean mark-up of graduate income over non-graduate income would be due to the provision of education. In this case, the government would have a net increase in the balance sheet of close to $\$ 11$ billion per year. At the other extreme, if potential graduates were innately more capable and could earn a 47 percent premium without a degree, the government would just break even from their 
current investment in higher education. With a thirty percent mark-up, the government balance sheet is positive in the order of $\$ 4.1$ billion per year.

Finally, we must ask what it all means. In Table 3 we have indicated that the contribution of higher education is important for the government to achieve budget balance. But so are many other aspects of government activity. Establishing the importance of economic phenomena is not necessarily a guide to policy. It does not follow that because higher education is important it should receive greater support from government. In determining how to spend its revenue, the government must choose the policies that yield the greatest improvement in social welfare. The issue is not whether higher education yields a positive return, but how this return compares to other uses of the money. It is also pertinent to ask to what extent the government would still derive the benefits of higher education if it did not incur the costs. It is only the additional higher education resulting from government investment which, strictly speaking, should be included on the benefit side of the cost-benefit analysis. That is, from a balance sheet perspective, expenditure on higher education should only be made by the government up to the extent that it increases the net benefit to the government (so if additional expenditure does not increase the net benefit, it should not be made, and if a decrease in expenditure increases the net benefit, then such a decrease should occur). A final important point is that a balance sheet approach provides information only on the direct financial costs and benefits to the government of higher education. While this is undoubtedly an important factor for the determination of government higher education funding decisions, there are other potentially important considerations, including the existence of public good properties of higher education and the implications of funding decisions for equity.

The analysis does indicate, however, that under a plausible set of assumptions, higher education more than pays its way, and government outlays to higher education could be considerably increased without endangering this net contribution to government spending.

\subsection{Potential extensions}

There is a wide range of studies that might be undertaken to further test the sensitivity of the results to our assumptions. These include varying assumptions on the per-student cost function, the teaching share of expenditure, the graduate wage mark-up, the proportion of equivalent full-time employment which graduates comprise (e.g. adjust for employment rates), the HECS repayments by field, and the basis for future projections. Incorporating selfemployment income into the analysis would also potentially produce a more accurate representation of the net benefit to the government. Likewise, attempting to adjust for 
differences between actual and counterfactual outcomes in the incidence of and earnings from part-time work and in the extent of welfare dependence could produce additional useful insights. It may also be informative to undertake separate analysis for males and females, between whom significant differences may exist. 


\section{References}

Australian Bureau of Statistics (ABS) (2001a) Australian Social Trends, Catalogue No. 4102.

ABS (2001b) Labour Force, Australia, Catalogue No. 6202.

ABS (2001c) Average Weekly Earnings, Australia, Catalogue No. 6302.

Australian Taxation Office (ATO) (2001) information on website at www.ato.gov.au

Borland, J., P. Dawkins, D. Johnson, and R. Williams (2000) - The Melbourne Economics of

Higher Education Research Program Report No 1, Report to the Vice-Chancellor, University of Melbourne.

Department of Education, Training and Youth Affairs (DETYA) (1998) Selected Higher Education Statistics: Research Expenditure, AGPS.

DETYA (1989-1993) (annual publication) Selected Higher Education Statistics, AGPS.

DETYA (1994-2000a) (annual publication) Selected Higher Education Finance Statistics, AGPS.

DETYA (1994-2000b) (annual publication) Selected Higher Education Student Statistics, AGPS.

DETYA (2000) Annual Report, AGPS.

Karmel, T. (1995) 'The impact of increasing education levels on the Australian workforce,' unpublished PhD dissertation, Australian National University.

Miller, P. and C. Mulvey (1997) 'Computer skills and wages,' Australian Economic Papers, $36,106-113$. 


\section{Appendix 1: Equations employed to estimate net benefits}

\section{A1.1 Costs}

The total cost to the government of field $i$ in year $t$ is equal to the sum of the costs of field $i$ across all $K_{t}$ universities which were operating in year $t$ :

$$
C_{i}^{t}=\sum_{k=1}^{K_{t}} C_{i k}^{t}
$$

The cost to the government in year $t$ of each field $i$ at university $k, C_{i k}^{t}$, is derived using information on government funding of each university, the share of university funds allocated to research (versus teaching), and enrolments and student-staff ratios by field of study for each university. Specifically, the total cost to the government of teaching at each university, $C_{k}^{t}$, is first derived using the information on government funding of each university and the research share of university expenditure. The cost of each field at each university is then calculated by assuming costs are directly proportional to the number of teaching staff in the field at the university.

Formally, the total year $t$ teaching costs to the government of university $k, C_{k}^{t}$ are calculated as:

$$
C_{k}^{t}=\left(T_{k}^{t}+H E C S_{k}^{t}\right)\left(1-r_{k}^{98}\right)\left(\frac{1-r^{t}}{1-r^{98}}\right)
$$

where $T_{k}^{t}$ is total direct Commonwealth government grants to university $k$ in year $t, H E C S_{k}^{t}$ is the value of university $k$ receipts from the Higher Education Contribution Scheme trust fund in that year, $r_{k}^{98}$ is the research share of expenditure for university $k$ in $1998, r^{98}$ is the research share for all universities in 1998, and $r^{t}$ is the research share for all universities in year $t$. The research percentage for a particular university may change over time but the research intensity of a university with respect to another remains constant over the period of the analysis. This information is reported in DETYA (1998), DETYA (1989-1993) and DETYA (1994-2000a).

Given $C_{k}^{t}$, the year $t$ cost of field $i$ at university $k, C_{i k}^{t}$, is then calculated as: 


$$
C_{i k}^{t}=\left(\frac{n_{k}^{t} / s_{i k}^{t}}{\sum_{i=1}^{I} n_{k}^{t} / s_{i k}^{t}}\right) C_{k}^{t}
$$

where $n_{i k}^{t}$ is the number of (full-time equivalent) students enrolled in field $i$ at university $k$ in year $t$ and $s_{i k}^{t}$ is the year $t$ student-staff ratio in field $i$ at university $k$, both of which are available from DETYA (1989-1993) and DETYA (1994-2000b). The fraction $\left(n_{k}^{t} / s_{i k}^{t}\right)$ is the number of fulltime equivalent teaching staff in field $i$ at university $k$, and the sum over I fields is the total number of full-time equivalent teaching staff at the university.

\section{A1.2 Revenue}

Additional revenue, flowing to the federal government as a result of tertiary education, is calculated for each field of qualification. Average graduate and non-graduate wages are defined by:

$$
\bar{w}^{t}=e^{t} w_{G}^{t}+\left(1-e^{t}\right) w_{N}^{t}
$$

and

$$
w_{G}^{t}=(1+m) w_{N}^{t}
$$

where $\bar{w}^{t}$ is the mean wage of all workers in year $t, w_{G}^{t}$ is the year $t$ mean wage of university graduates, $w_{N}^{t}$ is the year $t$ mean wage of non-graduates, $e^{t}$ is the proportion of employees who are university graduates in year $t$, and $m$ is the (time invariant) "mark-up" of the mean graduate wage over the mean non-graduate wage.

The mean graduate and non-graduate wages are not observed in the data available, but are derived as a function of observed variables $\left(e_{t}, \bar{w}^{t}\right)$ from equations (4) and (5) as:

$$
w_{G}^{t}=\frac{(1+m)}{\left(1+e^{t} m\right)} \bar{w}^{t}
$$

and

$$
w_{N}^{t}=\frac{w_{G}^{t}}{1+m}
$$




\section{Average graduate wages in each year by field of qualification}

The mean graduate wage in year $t$ can be expressed as a weighted average of the mean graduate wages by field:

$$
w_{G}^{t}=\sum_{i=1}^{I} e_{i}^{t} w_{i}^{t}
$$

where $e_{i}^{t}$ is the proportion of graduates in year $t$ with qualifications in field $i\left(\sum_{i=1}^{I} e_{i}^{t}=1\right)$ and $w_{i}^{t}$ is the year $t$ mean wage of graduates with qualifications in field $i$.

In the absence of data for each year on graduate wages and employment shares by field, $w_{i}^{t}$ is identified for each field using STE93. In particular, it is assumed that both relative wages across fields, and the proportion of graduates with qualifications in each field, are not time varying and are given by their values in STE93. That is, the mean wage of field $i$ relative to the aggregate mean graduate wage, $r_{i}$, is assumed in every year to be given by:

$$
r_{i}=\frac{w_{i}}{w_{G}}
$$

where $w_{i}, i=1, \ldots I$, is the mean wage for field $i$ and $w_{G}$ is the aggregate graduate mean wage in the STE93 data. Given knowledge of $w_{G}^{t}$ (from Equation (8), mean wages in each field in each year are therefore:

$$
w_{i}^{t}=r_{i} w_{G}^{t} \text { for } i=1, \ldots I
$$

\section{Increase in average earnings}

The increase in the mean wage of graduates over non-graduates by field in each year is calculated using the aggregate mean wage, the "mark-up", $m$, and the relative mean wage of each field, $r_{i}$. The time invariant mark-up of the mean wage of graduates with qualifications in field $i$ over the non-graduate mean wage is $m_{i}$, equal to $r_{i}(1+m)-1$, so that the mean wages of graduates in field $i$ is:

$$
w_{i}^{t}=\left(1+m_{i}\right) w_{N}^{t}
$$

Graduates are likely to have greater innate ability and therefore capacity to earn income than the workforce in general. We define this greater ability by a proportion, $s$ of the non-graduate wage. $s$ is a characteristic of graduates and not of their field of study so it carries no subscript. 
By assumption, $s>0$ and is time-invariant. The wage of graduates in the absence of a degree (the "counterfactual" wage) is then:

$$
\tilde{w}_{G}^{t}=(1+s) w_{N}^{t}
$$

We can therefore deduce the earnings increase due to the productivity effects of education for each field of study. It is $w_{i}^{t}-\tilde{w}_{G}^{t}$ or, substituting from above, $w_{N}^{t}\left(r_{i}(1+m)-(1+s)\right)$.

\section{Revenue to the Government}

The additional revenue to the federal government associated with higher education in field $i$ is equal to the increase in taxes from the increased income resulting from the productivity associated with the degree:

$$
R_{i}^{t}=E_{i}^{t}\left[T^{t}\left(w_{i}^{t}\right)-T^{t}\left(\tilde{w}_{i}^{t}\right)\right]+H_{i}^{t}
$$

where $E_{i}^{t}$ is the number of full-time equivalent employees with a degree in field $i$ in year $t$, $T^{t}($.$) is the year t$ (direct and indirect) tax payments associated with the weekly wage in parentheses (which is assumed to be received all year) and $H_{i}^{t}$ is the estimated HECS repayments in year $t$ by graduates with qualifications in field $i$.

$E_{i}^{t}$ is derived as:

$$
E_{i}^{t}=e_{D e g}^{t} e_{i} E^{t}
$$

where $e_{\text {Deg }}^{t}$ is the proportion of the population with a bachelor's degree or higher in year $t$ (obtained from ABS (2001a)), $e_{i}$ is the proportion of degree-holders with a degree in field $i$ in the STE93 and $E^{t}$ is the number of full-time equivalent employees in Australia in year $t$, obtained from ABS (2001b), and assuming two part-time jobs equal one full-time job. Tax payments $T^{t}$ (.) are based on the year $t$ income tax rates and an assumption that expenditure taxes account for $10 \%$ of income net of income tax and HECS repayments.

\section{A1.3 Cohort net benefit}

The internal rate of return for field $i$ is that value of $I R R_{i}$ which satisfies:

$$
\sum_{t=1999}^{2045} B_{i}^{t}\left(1+I R R_{i}\right)^{-(t-1999)}-\sum_{t=1999}^{2045} C_{i}^{t}\left(1+I R R_{i}\right)^{-(t-1999)}=0
$$


where $B_{i}^{t}$ is the field $i$ per student benefit accruing to the government in year $t$ and $C_{i}^{t}$ is the field $i$ per student cost incurred by the government in year $t$.

Costs to the government embodied in $C_{i}^{t}$ in Equation (15) comprise expenditure on higher education and forgone taxation revenue during the period in which the student is engaged in higher education study. Benefits embodied in $B_{i}^{t}$ comprise upfront HECS payments, repayments of deferred HECS debts, and additional taxation revenue derived from the higher earnings obtained by the student as a result of the education.

\section{Costs}

Per-student cost to the government of each year of study for field $i$ is assumed constant over the duration of the course and equal to:

$$
c_{i}=\frac{C_{i}^{1999}}{n_{i}^{1999}}
$$

where $C_{i}^{1999}$ is the total cost of field $i$ in 1999 and $n_{i}^{1999}$ is the number of enrolments in field $i$ in 1999 (equivalent full-time student units).

\section{Revenue}

Projected earnings for an individual commencing higher education in 1999 are based on an earnings equation estimated for native-born male full-time employees aged 15 to 64 using the seven ABS Income Distribution Surveys (IDS) conducted between 1982 and 1997/8. Specifically, the estimated wage equation implies the following equation for projected log weekly earnings:

$$
\left(w_{d} \mid X\right)=6.37+0.05 X-0.0011 X^{2}
$$

where $X$ is years of potential work experience (equal to zero in 2003 and 42 in 2045).

This produces an earnings series for degree holders in aggregate. Projected earnings are allowed to vary across fields by using the STE93, which has information on main field of study for highest educational qualification. The relative mean wage of each field of study was obtained for full-time employed native-born males aged 15 to 64, and multiplied by the aggregate projected wage at each experience level to produce the projected wages for each field: 


$$
\left(\mathrm{w}_{\mathrm{i}} \mid X\right)=\left(\frac{w_{i}^{1993}}{\bar{w}^{1993}}\right)\left(w_{d} \mid X\right)
$$

where $w_{i}^{1993}$ is the mean wage of individuals with a degree in field $i$, and $\bar{w}^{1993}$ is the mean wage of all degree-holders in ST93E.

The earnings of the individual in the absence of higher education (which we can label as projected "counterfactual" earnings) are also predicted, on a similar basis to that employed in the earlier analysis of the contemporaneous net benefit to the government. Projected earnings for non-degree-holders are derived from the estimated earnings equation, equal to:

$$
\left(w_{n} \mid X\right)=5.95+0.05 X-0.0010 X^{2}
$$

As per the current net benefit analysis, it is assumed that $80 \%$ of the difference in earnings between degree-holders and others is due to the productivity effect of the degree, with the remaining $20 \%$ the result of differences in innate ability. Thus, projected counterfactual earnings are equal to:

$$
\left(w_{d}^{c} \mid X\right)=\left(w_{n} \mid X\right)+0.2\left[\left(w_{d} \mid X\right)-\left(w_{n} \mid X\right)\right]
$$

Additional (per person) tax revenue deriving from the higher education in each year is calculated as the difference in the tax payable on projected actual earnings from the tax payable on projected counterfactual earnings, multiplied by the (full-time equivalent) employment rate.

\section{Appendix 2: Construction of a consistent set of fields across data sources}

The fields of study by which enrolments are reported by DETYA (1989-1996) for the period 1989 to 1996 are:

1. Agriculture, animal husbandry.

2. Architecture, building.

3. Arts, humanities and social sciences.

4. Business administration, economics.

5. Education.

6. Engineering, surveying. 
7. Health.

8. Law, legal studies.

9. Science.

10. Veterinary science.

11. Non-award courses.

The academic organisational units (1989-2000) and discipline groups (1997-2000) by which enrolments are reported by DETYA are:

1. Administration, business, economics, law.

2. Health sciences.

3. Education.

4. Science.

5. Maths, computing.

6. Agriculture, renewable resources.

7. Engineering, processing.

8. Built environment.

9. Humanities.

10. Social studies.

11. Visual/performing arts.

For each respondent, the Surveys of Education and Training record the field of highest educational qualification, the level of that qualification, current labour force status and earnings. This permits calculation of the relative earnings of degree holders by field of qualification. The STE93 records the main field of study for highest educational qualification for two different classifications of fields, one of which is also employed in the STE97.

The fields recorded only in STE93 are:

1. Administration, business studies, commerce.

2. Law.

3. Education. 


\section{Medicine.}

5. Science, maths.

6. Computing and information sciences.

7. Veterinary science, agriculture, forestry.

8. Engineering.

9. Architecture

10. Social studies, arts, humanities.

The fields recorded in both STE93 and STE97 are:

1. Business and administration.

2. Health.

3. Education.

4. Society and culture.

5. Science.

6. Engineering.

7. Architecture and building.

8. Agriculture.

The first (1993) set of fields provides a better match to the fields by which DETYA statistics are reported, and this set is preferred for the calculations of relative earnings by field. The censoring of earnings information is also a less severe problem in the 1993 survey than in the 1997 survey, providing an additional motivation for using the 1993 survey. ${ }^{13}$

Table 7 shows the 8 fields examined in the study and how they relate to the three classifications of disciplines in the various survey collections that are used.

\footnotetext{
${ }^{13}$ Earnings are censored above $\$ 1160$ per week in both STE93 and STE97, but this is a higher threshold relative to mean earnings in the STE93 due to nominal earnings growth between 1993 and 1997.
} 
Table 7: Matching of fields and disciplines

\begin{tabular}{|c|c|c|c|c|}
\hline \multicolumn{2}{|c|}{ Field for analysis } & \multicolumn{2}{|c|}{ DETYA } & \multirow{2}{*}{$\begin{array}{l}\text { STE93 } \\
\text { Fields } \\
\end{array}$} \\
\hline Number & Name & Fields, 1989-1996 & Disciplines, 1997-2000 & \\
\hline 1 & $\begin{array}{l}\text { Administration, } \\
\text { business, law }\end{array}$ & $\begin{array}{c}\text { Business } \\
\text { administration, } \\
\text { economics. } \\
\text { Law, legal studies. }\end{array}$ & $\begin{array}{c}\text { Administration, } \\
\text { business, economics, } \\
\text { law. }\end{array}$ & $\begin{array}{l}\text { Administration, } \\
\text { business studies, } \\
\text { commerce. } \\
\text { Law. }\end{array}$ \\
\hline 2 & Education & Education. & Education. & Education. \\
\hline 3 & Health & $\begin{array}{c}\text { Health. } \\
\text { Veterinary science. }\end{array}$ & Health sciences. & Medicine. \\
\hline 4 & Science & Science. & $\begin{array}{c}\text { Science. } \\
\text { Maths, computing. }\end{array}$ & $\begin{array}{c}\text { Science, maths. } \\
\text { Computing \& } \\
\text { Information Sciences. }\end{array}$ \\
\hline 5 & $\begin{array}{l}\text { Agriculture \& } \\
\text { related fields }\end{array}$ & $\begin{array}{l}\text { Agriculture, animal } \\
\text { husbandry. }\end{array}$ & $\begin{array}{l}\text { Agriculture, renewable } \\
\text { resources. }\end{array}$ & $\begin{array}{l}\text { Veterinary science, } \\
\text { agriculture, forestry. }\end{array}$ \\
\hline 6 & Engineering & $\begin{array}{l}\text { Engineering, } \\
\text { surveying. }\end{array}$ & $\begin{array}{l}\text { Engineering, } \\
\text { processing. }\end{array}$ & Engineering. \\
\hline 7 & $\begin{array}{c}\text { Architecture \& } \\
\text { related fields }\end{array}$ & $\begin{array}{l}\text { Architecture, } \\
\text { building. }\end{array}$ & Built environment. & Architecture. \\
\hline 8 & $\begin{array}{l}\text { Social sciences, } \\
\text { arts, humanities }\end{array}$ & $\begin{array}{l}\text { Arts, humanities, } \\
\text { social sciences. }\end{array}$ & $\begin{array}{c}\text { Social studies. } \\
\text { Humanities. } \\
\text { Visual/performing arts. }\end{array}$ & $\begin{array}{l}\text { Social sciences, arts, } \\
\text { humanities. }\end{array}$ \\
\hline
\end{tabular}

There are a number of classification conflicts:

- Field number 1: STE93 does not include economics and DETYA does.

- Field number 3: STE93 does not include veterinary science and DETYA does.

- Field number 5: STE93 includes veterinary science and DETYA does not.

- Field number 6: Surveying is included in DETYA 1989-1996 and processing is included in DETYA 1997-2001. Neither is in STE93.

- Field number 7: The DETYA category is broader, and includes disciplines such as building science.

- Field number 8: STE93 includes economics and DETYA does not. 


\section{University Library}

\section{- M M I E E R VA A gateway to Melbourne's research publications}

Minerva Access is the Institutional Repository of The University of Melbourne

Author/s:

JOHNSON, D;WILKINS, R

Title:

THE NET BENEFIT TO GOVERNMENT OF HIGHER EDUCATION: A "BALANCE SHEET" APPROACH

Date:

2003-06

Citation:

JOHNSON, D. \& WILKINS, R. (2003). THE NET BENEFIT TO GOVERNMENT OF HIGHER EDUCATION: A "BALANCE SHEET" APPROACH. Economic Papers: A journal of applied economics and policy, 22 (2), pp.1-20. https://doi.org/10.1111/j.1759-3441.2003.tb00339.x.

Persistent Link:

http://hdl.handle.net/11343/33620 